\section{Clinital : qotes:}

\section{MEDICAL, SURGICAL, OBSTETRICAL, AND THERAPEUTICAL.}

\section{A CASE OF TETANUS.}

BY D. Ligighton Davies, M.D., M.S. Lond.

THE patient, a healthy-looking farm labourer, aged 45 years, fell down on the road and sustained a cut over the right malar bone. The wound was not treated in any way and in the course of the next few days it kept "gathering and discharging." Six days later he felt his jaws becoming stiff and on the seventh day he was quite unable to open his mouth. When seen on the following day-i.e., eight days after the infliction of the wound-he was quite unable to move his lower jaw more than one-sixth of an inch. There was a suppurating wound over the right malar bone just below the outer margin of the orbit. From this a track passed beneath the skin for about one and a balf inches into the cheek and this contained a quantity of yellow pus. No bare bone was felt. There was slight chemosis of the conjunctiva of the right eye. He was intelligent and, except for the trismus, complained of no pain. There was complete right facial paralysis, the furrows on the right side of the forehead and the naso-labial fold being obliterated. There was inability to close the right eye and the lower eyelid had fallen away from the globe of the eye. The mouth was drawn over to the left. Both masseter muscles felt firm, but could be made harder by voluntary effort. There was no spasticity or paralysis of any other muscles of the body, the neck muscles being quite normal. There was no loss of sensation anywhere. Both knee-jerks were brisk and the plantar reflex was flexor. His pulse was normal in rate and his temperature was $99^{\circ} \mathrm{F}$. On the next day (i.e., the third day of the illness) laryngeal spasms developed. Sudden paroxysms of intense dyspncea would occur from time to time, during which there was tremendous action of the platysma myoides, giving the face a very hideous expression. He became almost maniacal during these paroxysms, tearing the dressings off his head and throwing himself about violently, and all the while he was bathed with a profuse perspiration. There was no cyanosis even during an attack and the pulse was strong. 'The temperature remained normal. In the intervals between the paroxysms the neck appeared to be a little stiff. To allay the paroxysms he was given a quarter of a grain of morphine hypodermically and this gave him relief for over 12 hours. At the expiration of that time he suddenly became worse, jumped ont of bed in a frenzy, and fell back dead. Unfortunately, a post-mortem examination was not permitted, but I succeeded in obtaining the trunk of the facial nerve of the right side as it left the stylo-mastoid foramen. To the naked eye it looked quite normal and microscopical examination showed an entire absence of pathological changes both in the neurilemma and the nerve tibres themselves.

Remarks. - The case was undonbtedly an example of infection with the tetanus bacillus, though at the time I overlooked the desirability of taking some of the pus for bacteriological examination. It differs, however, from the somewhat meagre description of this variety as given in the text-books I have consulted. The prognosis is stated to be somewhat more favourable in this variety than in the generalised type, but in this case death occurred three days from the onset of symptoms and nine days after the opportunity of infection occurred, and there was an entire absence of generalised spasm. There was no pharyngeal spasm but the laryngeal spasm was very distressing. The sudden terminatian of the disease in death may have been due to the laryngeal spasm or more probably to a sudden spasm of the cardiac muscle caused by the action of the toxin on the vagus centre. With regard to the underlying pathologioal changes leading to the facial paralysis, it has in the past been suggested that there was an ascending neuritis of the facial nerve. In the cases that have been examined no such changes have been found in the facial nerve and certainly there was no neuritis in this case. It is very probable that the paralysis is due to the action of an excessive dose of a virulent toxin on the nucleus of the facial nerve leading to the destruction of its cells. This is rendered more probable by the fact that the only muscles affected by the spasm were those which were innervated by nerves having their origin from nuclei in the neighbourhood of the seventh. The toxin must have reached the facial nucleus by passing ap the lymphatics accompanying the facial nerve, for clearly it was not likely to have been the blood-stream, seeing the region picked out was so localised and definite. This fact, too, may explain why it was that the facial nerve was paralysed and the other nerves escaped, for it may be conjectured that the virulent toxin meeting first the cells of the facial nucleus destroyed them, and that by the combination of some of the toxin with the protoplasm of the cells, which is known to occur, the virulence of the toxin was diminished so that its action was merely irritating and not destructive on the remaining nuclei. Wisbech.

CALCIUM SALTS AS A CARDIAO TONIC. By Jostre Stark, L.R.C.P. \& S. EdIN., L.F.P.S. GLASG

CaLCIUM salts have come much into prominence of late in the treatment of ulcers, both internal and external; they are also advocated for chilblains and to be given before operations likely to be attended with severe hæmorrhage. The well-known therapeutic effect of calcium salts is that they increase the coagulability of the blood. It is therefore quite easily understood why they are given in cases where hæmorrhage is anticipated but in cases of cardiac disease and pneumonia I think that some reasoning is required before accepting the same. Having under my care a married woman, aged 40 years, suffering from an ulcer on one of her legs, which seemed to be due to deep varicosity of veins I gave her 15 grains of calcium chloride three time a day. At the time I did not further examine her as she was fully dressed. I was called out on the third day of treatment to see her-she was complaining of numbness of the right side of the body and was cyanotic. The next day she was a little better but still had the feeling of "pins and needles" in her right arm and leg. On the following day she had complete hemiplegia. There is no doubt on account of the slow onset that the lesion was due to cerebral thrombosis. I may state that I had now further examined the patient and found that she had a mitral lesion. I thought of my treatment and the therapentic use of the same and came to the conclusion that the calcium salts had something to do with the condition of the patient. Sir James Barr has lately advocated calcium salts in pneumonia. It is well known that an ante-mortem clot is found in the pulmonary artery in most of the fatal cases of pneumonia. Then why should the practitioner endeavour to increase the coagulability of the blood ? Dr. W. Blair Bell says that it is only in certain cases that we should use the same. I do not think that Dr. Bell's method of examining the blood is applicable in general practice and therefore I would advise general practitioners at least not to treat pneumonia and diseases of the heart by the calcium salts.

Annfield Plain, R.S.O., Durham.

\section{HERNIA OF ILEUM PRESENTING OVER THE THORACIC WALL.}

By Hercules H. MacDonnell, M.D. Dub., SURGEON, LOUTH COUNTY INFIRMARY.

A MAN, aged 28 years, was admitted into the Louth County Infirmary, Dundalk, on Oct. 8th, 1906. On the previous day he had been knocked off his bicycle. On admission he complained of faintness and pain over the chest, and a small tumour about two inches in diameter was seen situated over the sixth and seventh ribs on the left side about two and a half inches from the border of the sternum; this was extremely painful to the touch, so much so that a thorough examination without the aid of an anæsthetic was not possible; for several reasons it was not considered advisable to administer one. The skin over the tumour had a slightly bluish appearance. A tentative diagnosis of fractured ribs with a possible hæmatoma was made. Pads were placed at either side of the tumour to avoid pressure and a broad flannel roller applied over the thorax. The bowels were freely moved on the next day. On the fourth day after admission, on removing the pads 